\title{
Stationarity of spot freight rates considering supply/demand effect
}

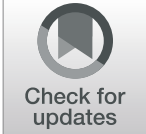

Koichiro Hayashi

\author{
Correspondence: koichiro.hayashi@ \\ nykgroup.com \\ NYK Line, 2-3-2 Marunouchi, \\ Chiyoda, Tokyo 100-0005, Japan
}

\begin{abstract}
The mean-reverting nature of freight rates is one of the important subjects in maritime economics. The classic understanding of maritime economics (and that of the shipping industry) suggests that freight rate processes are mean-reverting and approach the level decided by the demand/supply ratio. However, statistical tests on freight rate processes often reveal these processes to be non-stationary, which means the processes would not have a mean-reverting nature. In this study, we investigated the mean-reverting nature of Panamax freight rates (Baltic Panamax 4T/ ( Average) for two "means": the actual freight rate process itself, and the deviation process of actual freight rates from estimated ones based on the demand/supply ratio. The AR (1) model can be applied to both processes, and their autoregressive coefficient $\varphi$ was between 0 and 1. In the actual freight process, $\varphi$ was close to 1 , and a unit root test failed to reject that the process is non-stationary. By contrast, in the deviation process, $\varphi$ was sufficiently smaller than 1, and a unit root test rejected that the process is non-stationary. The result can resolve the contradiction between two views on mean-reverting nature; if we focus on the actual freight rate process itself and do not consider demand/supply, the process is non-stationary and does not have a mean-reverting nature. If we focus on the deviation process of the actual freight rates from the level decided by the demand/supply ratio, the process is stationary and tends to approach zero.
\end{abstract}

Keywords: Drybulk, Market, Stationarity, Cyclical fluctuation

\section{Springer Open}

\section{Introduction}

The purpose of this study is to resolve the contradiction of two different views on the mean-reverting nature of the dry-bulk shipping market; one view is by the shipping industry and the other is by academia. In this study, "mean-reverting nature" is defined as gradual decreases in deviation over subsequent periods after the freight rate deviates from equilibrium.

In the shipping industry, it is widely believed that a freight rate is decided by supply and demand over the long run, and once deviation occurs as the result of a short-term reason, the deviation will gradually fade away. Many well-known industry research firms such as Clarksons Researcha (2020) and SSY (2019) publish dry-bulk shipping market analysis reports that are based on this view. This understanding is in line with

(c) The Author(s). 2020 Open Access This article is licensed under a Creative Commons Attribution 4.0 International License, which permits use, sharing, adaptation, distribution and reproduction in any medium or format, as long as you give appropriate credit to the original author(s) and the source, provide a link to the Creative Commons licence, and indicate if changes were made. The images or other third party material in this article are included in the article's Creative Commons licence, unless indicated otherwise in a credit line to the material. If material is not included in the article's Creative Commons licence and your intended use is not permitted by statutory regulation or exceeds the permitted use, you will need to obtain permission directly from the copyright holder. To view a copy of this licence, visit http://creativecommons.org/licenses/by/4.0/. 
the classic understanding of maritime economics which appeared on standard textbooks such as Stopford (2009) or Karakitsos and Varnavides (2014).

On the other hand, academia has had a different view since a new time-series analysis concept founded by Granger and Newbold (1974) was introduced to maritime economics in the late 1990s. One of the key concepts of the new time-series analysis is stationarity. In a non-stationary time-series process, a deviation that occurs at a certain time does not fade away in subsequent periods but rather accumulates. Because a regression analysis between two non-stationary time-series process produces an incorrect result called a 'spurious regression,' many past studies were reviewed to examine whether time-series used in these studies were non-stationary. This review was applied to the dry-bulk shipping market by Veenstra and Franses (1997) and other researchers. Many of these studies concluded that freight rate time-series processes are non-stationary.

For a long time, both the shipping industry and academia have had little motivation to resolve this contradiction.

The reason in academia is that it lacked the expertise to analyze supply and demand for newly introduced dry-bulk shipping market indicators. In the late 1990s, when the new time-series analysis method was introduced to maritime economics, the Baltic Exchange began publishing dry-bulk market indicators by ship type and high frequency (Baltic Exchange, 2020). Because of the prevalence of these indices in the industry, academic studies started to adopt them. However, supply and demand data required for analysis of these specific ship types and frequencies differ from those used in past studies. Therefore, academic researchers faced difficulty to analyze supply and demand.

The reason industry lacked the motivation to resolve the contradiction is that industry had lost its confidence in a statistical approach and thus given it less attention. Early in the twenty-first century, the dry-bulk shipping market was extremely volatile because of the shipping boom and bust. People in industry had thus become very skeptical about whether statistical approaches could explain the markets.

However, in recent years the industry recovered its confidence in statistical approaches and can no longer afford to leave this problem unresolved for two reasons. One reason concerns the concept. As mentioned above, the shipping industry relies on the concept that a freight rate is determined by supply and demand over the long run. The view that a deviation in freight rate does not fade in subsequent periods erodes industry confidence in statistical approaches. The other reason concerns analysis technique. Regression analysis is widely used within the industry. If a time-series process is used in the analysis, regression analysis cannot be applied to the process because of 'spurious regression'.

The author attempted to combine his knowledge as an industry expert with academic methods to resolve this issue. More specifically, the author selected supply and demand data corresponding to the Baltic Exchange index to calculate the demand/supply ratio. Time-series analyses on (1) theoretical freight rates determined by the demand/supply ratio and (2) actual freight rates were then conducted. If an actual freight rate timeseries process is non-stationary but a deviation time-series process of theoretical freight rates from actual ones is stationary, we can say that a contradiction between industry and academia is resolved. This study requires industry knowledge of the dry-bulk shipping market, especially concerning what supply and demand data should be employed. 
The author has been working for 10 years as a chief analyst of dry-bulk shipping at a Japanese shipping company, and an annual report (NYK 2019) edited by the author is regarded as one of the authorized sources of dry-bulk supply and demand fundamentals in Japan. Therefore, the author believes his industry knowledge can contribute to academia.

The reminder of this paper is structured as follows. Section 2 introduces the preceding studies. Section 3 presents the approach and data profile. Section 4 presents the result of the statistical analysis. The final section concludes this paper.

\section{Literature survey}

This study conducted literature surveys in three areas: 1) survey papers on studies about the dry-bulk shipping market, 2) studies to explain the reason of non-stationarity in freight rate time-series, and 3) recent studies employing demand and supply information other than traditional ones (i.e., cargo volumes and fleet capacity). Survey papers of 1) are required to confirm whether the understanding of this study about the past research history is correct. Studies of 2) are required to confirm whether the research question of this study has not been taken up in past studies. And studies of 3) are required to validate whether the research question of this paper has value in the current academic context.

As for survey papers on studies about the dry-bulk shipping market, Goulielmos has published a series of survey papers. Goulielmos (2019) covers studies from 1934 to 1996. This paper categorizes major studies in the target period into four groups: Dutch Center, Zannetos and colleagues, Norwegian Center, and English Center. All groups regarded demand and supply effects on the freight rate as an important subject. Goulielmos (2018a) covers studies from 1996 to 2005, when the new time-series analysis technique was introduced to maritime economics. This paper explains that during that period many past studies are identified as inappropriate because they relied on spurious regressions. Also, the paper analyzed the results of 36 important studies. Many of those studies resulted that a freight rate time-series process is non-stationary. Goulielmos (2018b) covers around 60 studies from 2006 to 2016. This paper reveals that the relationship between freight rate and demand/supply is not a major research subject in this period. Instead, the major research subjects are the volatility of the freight rate process and the relationship among multiple freight rate processes (e.g., different vessel sizes or futures). Glen (2006) is another survey paper about the impact of the introduction of the new time-series analysis technique on maritime economics. According to this paper, some major changes happened after the introduction of the technique. First, more detailed (on specific vessel sizes) and highly frequent freight rate processes are used in studies. Second, volatility became a more important subject than the freight rate itself. Third, the relationship between multiple freight rate processes (e.g., different vessel sizes or futures) are major research subjects other than the relationship between freight rate and demand/supply. These survey papers support the understanding of this study.

As for the studies to explain the reason for non-stationarity in freight rate timeseries, only a few papers exist and none of them used demand and supply data as an explanation. Tvedt (2003) paid attention to the exchange rate between the U.S. dollar and Japanese yen and concluded that the freight rate process expressed in U.S. dollars 
is non-stationary but that expressed in Japanese yen is stationary. Adland and Cullinane (2006) and Koekebakker et al. (2006) focused on the market situation and concluded that the freight rate process is stationary only in extreme markets (e.g., very high or very low) and during other periods it is non-stationary. These results suggested that the approach of this study to use demand and supply data for the explanation of nonstationarity has originality.

As for recent studies employing demand and supply information other than traditional ones, studies using AIS data are emerging. AIS, an abbreviation for Automatic Identification System, is a system to send, receive and share information related to ship movement. This information includes current position, speed and direction of travel, and a variety of supplementary data. Use of AIS was mandated by the IMO in 2002 for all ships of 300 gross tonnage and upwards engaged on international voyages (IMO, 2020). Although AIS was originally introduced for the safety of navigation, some studies have begun to use AIS data as a demand/supply indicator because AIS data contains the laden/ballast (empty) indicator. One of these studies is Adland et al. (2017), which uses AIS data to estimate trade volume of crude oil tankers. At the moment, these new studies do not negate the value of studies that use a traditional demand/supply indicator. There are two reasons. First, these new studies have only just started, and not many research topics have been uncovered, including stationarity. Second, AIS data before 2015 has not been captured and is not available for analysis.

\section{Methodology}

This study assumes the below model to investigate the relationship among freight rate, supply and demand, and their deviation:

Actual freight rates (a) = Estimated freight rates based on demand/supply (b) + Deviation (c).

The below steps are then taken.

- Obtain the formula to derive estimate freight rates from demand and supply

- Calculate estimated freight rates and their deviation from actual ones

- Examine the statistical characteristics of each time-series

As for the freight rates, target shipping market, the target period, and the market indicator for the market should be decided. This study focuses on the market of Panamax size bulkers. This is because the Panamax market is the most liquid and competitive market among all vessel sizes (Capesize, Panamax, Handysize and Handymax). The Handymax and Handysize markets are divided into commodities and therefore are less liquid than markets of larger vessels. On the other hand, the Capesize market depends almost solely on iron ore trades, especially between Australia/Brazil and China. Also, a few big mining companies hold large trading shares and therefore have a strong influence on the market. The Panamax market has two major cargoes (i.e., coal and grain), and their markets are integrated. Also, there are no players holding a dominant share, such as in iron ore. The examined period begins from February 2009, when the market disturbance caused by the financial crisis concludes, and ends in May 2017. The market indicator used in this study is the logarithmic Baltic Panamax 4 T/C to express the exponential relationship between freight rates and the demand/supply ratio. 
As for the demand and supply data, this study employs the fleet capacity of Panamax vessels as the supply indicator and export cargo volumes as the demand indicator. As for fleet capacity, some shipping information vendors publish monthly statistics. This study employed the data of Clarksons Research. This is because Clarksons Research is widely recognized as the most reliable information vender in the dry-bulk shipping market. Its data can be downloaded from its online database "Shipping Intelligent Network" (Clarksons Research 2019). The field name is "Fleet Development (in DWT)." Fleet capacity can be affected by other factors, such as the average speed of vessels or non-operational periods of vessels (caused by drydock, lay-up, and congestion). These factors are not used in this study. The main reason is that they are difficult to obtain over the target period. Also, the author concludes that in the target period these factors have changed only gradually and do not heavily affect short-term deviation. As for export cargo volumes, the study used the combined export volumes of major export countries of Panamax cargoes. The list is shown in Table 1. This list can be considered to be adequate because shipments from minor export countries are usually arranged off-market and do not affect the shipping market. Some information venders provide a customs-statistics download service. This study employs IHS's online database "Global Trade Atlas" (IHS Markit, 2019). The transport distance of each cargo can affect vessel demand (in ton-mile), but this factor is not included in this study. As with fleet capacity, these are difficult to obtain over the target period and are considered to have changed only gradually and do not heavily affect short-term deviation.

Based on the above freight rates, supply and demand, this study assumes simple linear regression between freight rates and the demand/supply ratio as below.

Estimated freight rate $(b)=\alpha \times($ demand/supply ratio $)+\beta$.

In this study, the mean-reverting nature is determined by stationarity. The following four steps are used to determine whether a time-series process is stationary or not. The first step is to illustrate the movement of values in a time-series and try to identify whether there are any anomalies such as unnatural regularity or change of movement over the period. The second step is to test stationarity with a statistical method. This study employs the Augmented Dickey-Fuller test. The Augmented Dickey-Fuller test was developed by Said and Dickey (1984) as an expansion of the Dickey-Fuller test (Dickey and Fuller 1979) and is widely used in statistics and econometrics as a method for testing stationarity. The third step is to apply the AR (1) model to time-series processes to identify the strength of the mean-reverting nature. An AR (1) process can be expressed as below:

$$
\mathrm{R}_{\mathrm{t}}=\phi \times \mathrm{R}_{\mathrm{t}-1}+\mu+\varepsilon_{\mathrm{t}}
$$

Table 1 Major export countries of Panamax cargoes

\begin{tabular}{ll}
\hline Commodity & Export Countries \\
\hline Coking Coal & USA, Australia and Canada \\
Steam Coal & Australia, South Africa and Indonesia \\
Wheat & USA, Canada, Russia and Australia \\
Corn & USA, Argentina, Ukraine and Brazil \\
Soybeans & USA, Brazil and Argentina \\
\hline
\end{tabular}


Where $R_{t}$ is a value of period $t, \mu$ is constant and $\varepsilon_{t}$ is white noise. If $\phi$ is 1 , the effect of the value of this period never fades away and the process is non-stationary. If $\phi$ is 0 , the value of this period does not affect the value of the next period at all. The fourth step is to test autocorrelation and autocovariance of residual $\varepsilon_{\mathrm{t}}$ for each time-series process. If autocorrelation or autocovariance exists, it means that there are hidden structures that are not represented by the AR (1) model, and therefore applying the model is not appropriate. This study employs the Ljung-Box test to identify autocorrelation and autocovariance. The Ljung-Box test was developed by Ljung and Box (1978) and is widely used in statistics and econometrics as a method for testing the existence of autocorrelation and autocovariance.

\section{Analysis result}

First, the obtained parameter $\alpha$ and $\beta$ by simple regressions are 0.0902 and 2.2007, respectively. e.g.,

Estimated freight rate $=0.0902 \times($ demand/supply ratio $)+2.2007$

Figure 1. is a visual comparison of actual and estimated freight rates calculated by the above parameters. (The left axis scale is the logarithmic value of freight rates in USD/ day.) Fig. 2. is an illustration showing the deviation of estimated freight rates from actual ones. (The left axis scale is the difference of the logarithmic value of actual and estimate freight rates in USD/day.) In both graphs, there are no anomalies such as unnatural regularity or change of movement over the period. As a result, these time-series processes are suitable for statistical analysis. Figure 1. shows that actual and estimate freight rates are almost moving together, including their peak and bottom values and timings. Figure 2. seems to illustrate a cyclical fluctuation with a length of 3 to 4 years. This cyclical fluctuation may be caused by the time lag between order and delivery of vessels, as discussed in Hayashi (2019). However, the fluctuation is small, and autocorrelation (in the later step) is not observed in actual freight rates and deviation. Therefore, the author decided not to include this cyclical fluctuation in this study.

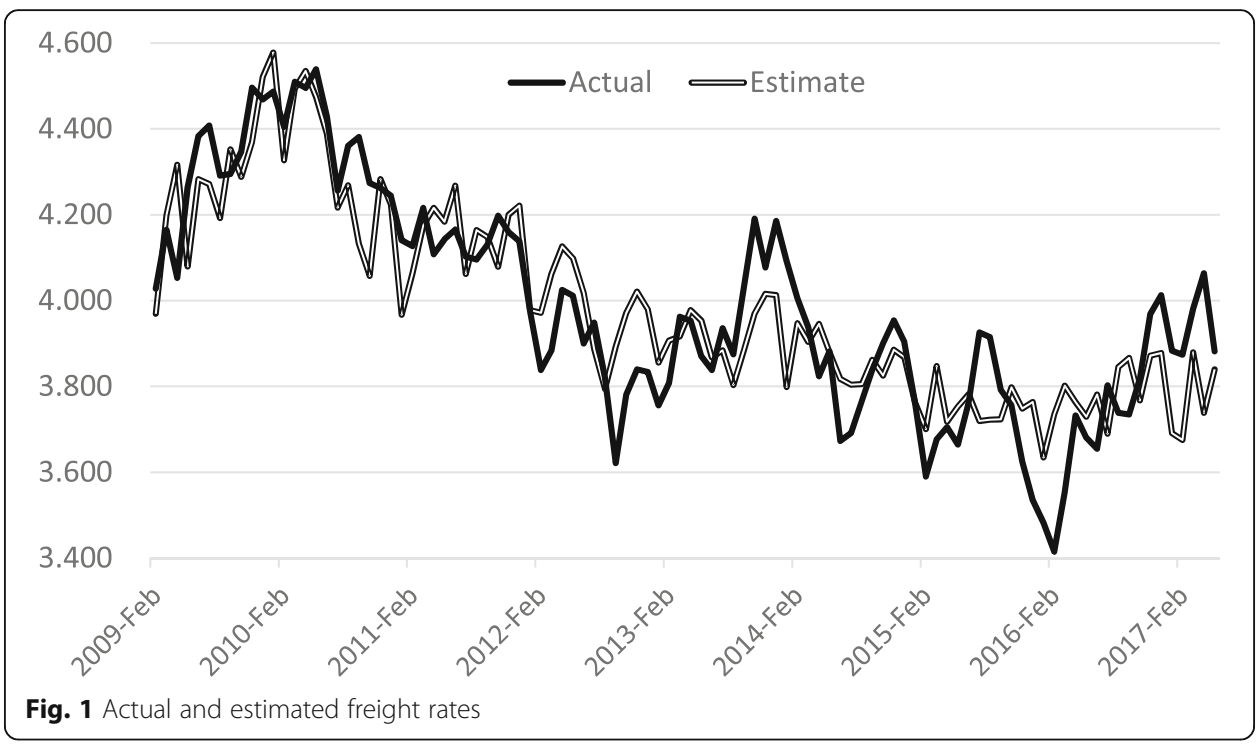




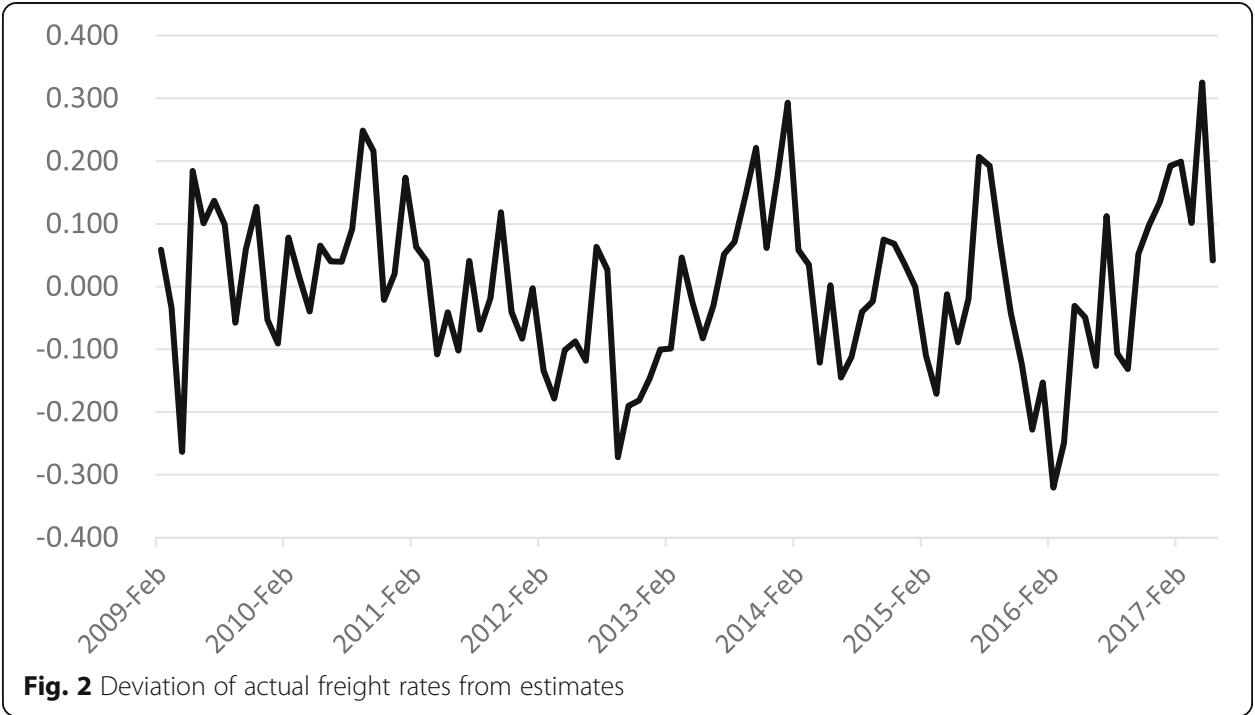

Given the above estimation, descriptive statistics for the time series are calculated in Table 2. The value of freight rates in Table 2. is the logarithmic value of original freight rates in USD/day.

Augmented Dickey-Fuller tests are then applied to these three time-series processes to examine stationarity. The lag length is selected by Schwarz Bayesian information criterion. The results are in Table 3. These results failed to reject the non-stationarity at $10 \%$ level of significance and therefore do not support the stationarity of the actual and estimated freight rates. On the other hand, the result for the deviation process rejected the non-stationarity at $5 \%$ level of significance. This result means that both the actual and estimated freight rate processes are non-stationary, while their deviation is stationary. These results mean that actual and estimated freight rates are cointegrated.

To investigate the detailed characteristics of the mean-reverting nature, we applied the AR (1) model to these processes. The parameters of these models are in Table 4. Also, we tested autocorrelation and autocovariance of residual $\varepsilon_{t}$. Tests for all three residuals rejected the presence of autocorrelation and autocovariance at $5 \%$ level of significance. This result means $\varepsilon_{\mathrm{t}}$ of both actual freight rates can be regarded as white noise. Therefore, fitting the AR (1) model for these three time-series processes is valid. Comparing the values of $\phi$, which shows a power of mean-reverting, $\phi$ of actual freight rates is greater than 0.9 , but $\phi$ of deviation is about 0.5 . Therefore, we can confirm that the deviation has a mean-reverting nature, but a mean-reverting nature for the actual freight rates is far less significant and therefore statistically rejected.

Table 2 Descriptive statistics for actual and estimated freight rates

\begin{tabular}{llll}
\hline & Actual Freight Rates & Estimated Freight Rates & Deviation \\
\hline Number of observations & 100 & 100 & 100 \\
Mean & 3.9898 & 3.9898 & 0.0000 \\
Maximum & 4.5390 & 4.5779 & 0.3251 \\
Minimum & 3.4150 & 3.6344 & -0.3203 \\
Std. Deviation & 0.2602 & 0.2265 & 0.1280 \\
\hline
\end{tabular}


Table 3 Results of Augmented Dickey-Fuller tests

\begin{tabular}{lcc}
\hline & Value & Lags \\
\hline Actual Freight Rates & -2.496 & 4 \\
Estimated Freight Rates & -2.303 & 4 \\
Deviation & -3.723 & 4 \\
Critical values $-1 \%$ & -4.052 & \\
Critical values $-5 \%$ & -3.452 & \\
Critical values $-10 \%$ & -3.153 & \\
\hline
\end{tabular}

\section{Conclusion and further discussion}

This study examined the stationarity and mean-reverting nature of freight rates. These issues are important for maritime economics and have been discussed for a long time. The outcome is that the freight rate process itself is non-stationary and therefore not mean-reverting, while the deviation process of freight rates from estimation by the demand/supply ratio is stationary and mean-reverting. This outcome is meaningful because it can integrate two inconsistent views on freight rates. As mentioned in Section 1 , whether a freight rate is stationary or not has great significance in the industry. For example, if the market falls sharply in the short term, the effect remains perpetually if the process is non-stationary, but it will fade away if the process is stationary. The result of this study will help industry analysts to build a model to handle market fluctuation properly.

In future studies, other frequencies (especially frequencies shorter than those in this study) should be examined to determine whether they would produce the same outcome. Because of the spread of AIS data in recent years, some supply and demand information, such as laden/ballast ratio, can be obtained almost in real-time and with higher frequency. Comparing the outcome of such future studies with this study may provide not only the difference between frequencies but also the difference in characteristics of supply and demand information between AIS data and traditional methods (trade volume and fleet capacity).

It is also important to extend the analysis to markets of other ship sizes and types, and other time periods. As described above, the Panamax market is the most liquid and competitive market. Therefore, markets of other sizes and types may indicate different characteristics. Also, the tanker market is a good candidate to apply this model for better market analysis. Dry-bulk and tanker markets have very similar market structure. As for time period, the period examined in this study is when the dry-bulk market was stable and the relationship between freight rates and the demand/supply ratio was consistent. By including the change of the relationship between freight rates and the demand/supply ratio, it will be possible to examine longer time periods containing structural market changes.

Table 4 Parameters of AR (1) models

\begin{tabular}{llll}
\hline & Actual Freight Rates & Estimated Freight Rates & Deviation \\
\hline Autoregression coefficient $\varphi$ & 0.9258 & 0.8849 & 0.5187 \\
Intercept $\mu$ & 3.6937 & 3.5305 & 0.0000 \\
Variance of innovation 02 & 0.0098 & 0.0113 & 0.0121 \\
\hline
\end{tabular}




\section{Acknowledgements}

This article is presented as a reviewed paper at IAME 2020.

The article processing charge for this work accepted by IAME2020 is supported by China Merchants Energy Shipping

\section{Author's contributions}

The author(s) read and approved the final manuscript.

\section{Funding}

The research is not funded by any funding bodies.

\section{Availability of data and materials}

The datasets used and/or analysed during the current study are available from the author on reasonable request.

\section{Competing interests}

The author declares that he has no competing interests.

Received: 31 August 2020 Accepted: 25 October 2020

Published online: 20 November 2020

\section{References}

Adland R, Cullinane K (2006) The non-linear dynamics of spot freight rates in tanker markets. Transp Res E 42:211-224 Adland R, Jia H, Strandenes SP (2017) Are AIS-based trade volume estimate reliable? The case of crude oil exports. Maritime Policy Manage 44(5):657-665

Baltic Exchange (2020) A history of the Baltic indices. http://www.balticexchange.cn/html/marketreport/uploadfiles/170326/2 01703261844079653.pdf. Accessed 19 Jan 2020

Clarksons Research (2019) Shipping Review \& Outlook 2019 autumn. Clarksons Research, London

Clarksons Research (2020) Shipping intelligence network. https://sin.clarksons.net/. Accessed 18 Jan 2020

Dickey D, Fuller W (1979) Distribution of the estimators for autoregressive time series with a unit root. J Am Stat Assoc 74(366):427-431

Glen DR (2006) The modelling of dry bulk and tanker markets: a survey. Maritime Policy Manage 33(5):431-445

Goulielmos A (2018a) Maritime econometrics: Models of dry cargo ships and tankers, 1996-2005., Survey. Mod Econ 9:21962223

Goulielmos A (2018b) Maritime economic modelling: a survey, 2006-2016. Mod Econ 9:2064-3091

Goulielmos A (2019) A brief history of maritime econometrics, 1934-2012. Mod Econ 10:730-756

Granger C, Newbold P (1974) Spurious regressions in econometrics. J Econ 2(2):111-120

Hayashi K (2019) Cyclical fluctuation in dry bulk market caused by non-demand/supply factors, proceedings of the

conference of the International Association of Maritime Economists 2019, Athens, Greek, June

IHS Markit (2019) Global Trade Atlas. https://www.gtis.com/gta/. Accessed 10 Oct 2019

IMO (2020) AIS transponders. http://www.imo.org/en/OurWork/safety/navigation/pages/ais.aspx. Accessed 112020 Jan

Karakitsos E, Varnavides L (2014) Maritime Economics: A Macroeconomic Approach. Palgrave Macmillan, New York Koekebakker S, Adland R, Sodal S (2006) Are spot freight rates stationary? J Transport Econ Policy 40(3):449-472

Ljung G, Box G (1978) On a measure of a lack of fit in time series models. Biometrika 65:297-303

NYK Line (2019) 2019 outlook for the dry-bulk and crude-oil shipping markets. The Japan Shipping Exchange Inc., Tokyo

Said S, Dickey D (1984) Testing for unit roots in autoregressive-moving average models of unknown order. Biometrika. 71(3): $599-607$

SSY (2019) Monthly shipping review 13th September 2019. SSY, London

Stopford M (2009) Maritime economics, 3rd edition. Routledge, London

Tvedt J (2003) A new perspective on price dynamics of the dry bulk market. Marit Policy Manag 30:221-230

Veenstra A, Franses P (1997) A co-integration approach to forecasting freight rates in the dry bulk shipping sector.

Transportation Res A 31:447-458

\section{Publisher's Note}

Springer Nature remains neutral with regard to jurisdictional claims in published maps and institutional affiliations.

\section{Submit your manuscript to a SpringerOpen ${ }^{\circ}$ journal and benefit from:}

- Convenient online submission

- Rigorous peer review

- Open access: articles freely available online

High visibility within the field

- Retaining the copyright to your article

Submit your next manuscript at $\boldsymbol{\nabla}$ springeropen.com 